The superficiality of the implant base and the late appearance of the recurrent neoplasia could rule out the hypothesis of an incomplete resection of the original tumor, raising the question about an unexplained potential growth from a second "pretumorous" metasynchronous cellular focus. To our knowledge, this issue is not supported by the literature to date. All the echocardiographic tests performed in the 10-year follow-up from the first operation showed negative results, confirming the recent growth of the recurrence.

We conclude that it is impossible to exclude a late neoplastic recurrence after resection of a cardiac hemangioma. The causes of recurrence are not completely known. A long-term echocardiographic follow-up is mandatory to monitor for representation of hemangiomas.

\section{References}

1. Straus R, Merliss R. Primary tumors of the heart. Arch Pathol. 1945; 39:74-8.

2. Brizard C, Latremouille C, Jebara VA, et al. Cardiac hemangiomas. Ann Thorac Surg. 1993;56:390-4.

3. Van Trigt P III, Sabiston DC Jr. Tumors of the heart. In: Sabiston DC, Spencer FC. 6th ed. Philadelphia: WB Saunders; 1995. Surgery of the chest, Vol 2:p. 2069-86.

4. Abad C, Campo E, Estruch R, et al. Cardiac hemangioma with papillary endothelial hyperplasia: report of resected case and review of literature. Ann Thorac Surg. 1990;49:305-8.

5. Scully RE, Mark EJ, McNeely BU. Case records of the Massachusetts General Hospital. Case 4-1983. N Engl J Med. 1983;308:20614.

\title{
Successful treatment of a mycotic aortic arch aneurysm associated with an isolated left vertebral artery
}

\author{
Yuji Naito, MD, Masato Nakajima, MD, Hidenori Inoue, MD, Eiki Mizutani, MD, and Koji Tsuchiya, MD, Kofu-shi, Japan
}

M ycotic aneurysms are rare in this age of antibiotics, but they are life-threatening. The isolated left vertebral artery (ILVA) is a left vertebral artery originating directly from the aortic arch. It is one of the most common aortic arch branch anomalies, occurring in about $4 \%$ of the general population. The case report presented here is of a mycotic aortic arch aneurysm associated with an ILVA.

\section{Clinical Summary}

A 65-year-old man was admitted to another hospital for investigation into back pain that had lasted for a few hours and disappeared spontaneously. He had reported a cough and febrile illness about 2 months earlier. He was not receiving any drugs, and his medical history was unremarkable. Chest computed tomographic findings led to a diagnosis of aortic arch aneurysm, and the patient was referred to us for surgical treatment. The patient was afebrile on admission. Vital signs were normal, as were cardiopulmonary sounds. Cardiovascular examination revealed a good pulse without bruits at all sites. Laboratory tests showed a leukocyte count of $9500 \times 10^{9}$ cells/L and a C-reactive protein level of $7.62 \mathrm{mg} / \mathrm{dL}$.

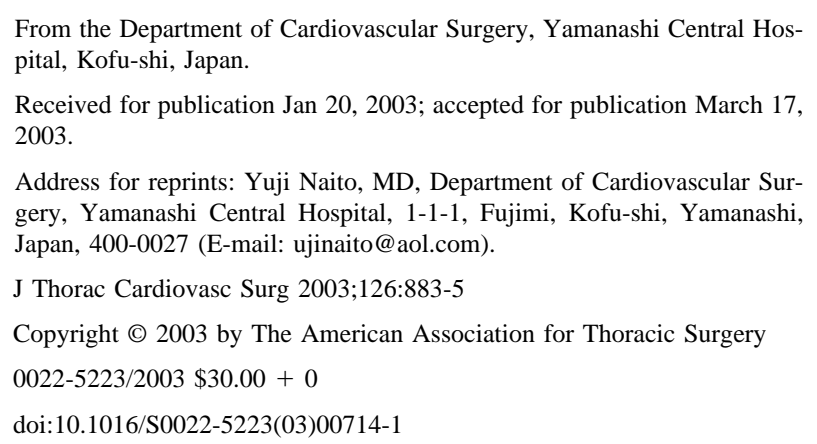

Chest radiography revealed a mildly enlarged mediastinal shadow and normal cardiothoracic ratio. Chest computed tomographic scan (Figure 1, $A$ and $B$ ) confirmed a multisaccular aneurysm of the aortic arch, and both magnetic resonance angiography (Figure 2) and digital subtraction angiography (Figure 1,B) depicted an ILVA arising from the aneurysmal wall.

We performed semiurgent surgery because the patient was at risk for rupture of the aneurysm. During surgery, dense adhesion around the aortic arch vessels was noted, probably caused by infection-induced inflammation. Total arch replacement with a 4-branched collagen-pretreated aortic arch graft (Hemashield Branched Graft; Meadox Medical, Oakland, NJ) was completed with selective cerebral perfusion. Cardiopulmonary bypass was established with ascending aortic and single right atrial cannulation. Under a condition of circulatory arrest at a rectal temperature of $28^{\circ} \mathrm{C}$, the aneurysm was opened, then selective cerebral perfusion was started through the innominate and left common carotid arteries. The aneurysmal wall was thickened and edematous, with some atherosclerotic lesions containing druses. The left subclavian artery (LSA) and ILVA were simply clamped. After careful inspection of the aorta, dissection was extended for utmost eradication of infected tissue toward healthy-looking aorta, where distal anastomosis was completed. After proximal graft anastomosis and LSA repair were completed, the shortened ILVA was reconstructed with a saphenous vein graft interposed between the native ILVA and the side of the graft branch anastomosed to the LSA. After all cervical vessels were reconstructed, cardiopulmonary bypass was stopped. The cardiopulmonary bypass, selective cerebral perfusion, circulatory arrest, and aortic crossclamping times were 164, 97, 49, and 82 minutes, respectively. Streptococcus pneumoniae, susceptible to cefazolin and to meropenem, was cultured from aortic lesion tissue. The patient was treated intravenously with $1 \mathrm{~g}$ cefazolin during surgery and $2 \mathrm{~g}$ meropenem after surgery. After 2 weeks of antibiotic therapy, he was discharged on 

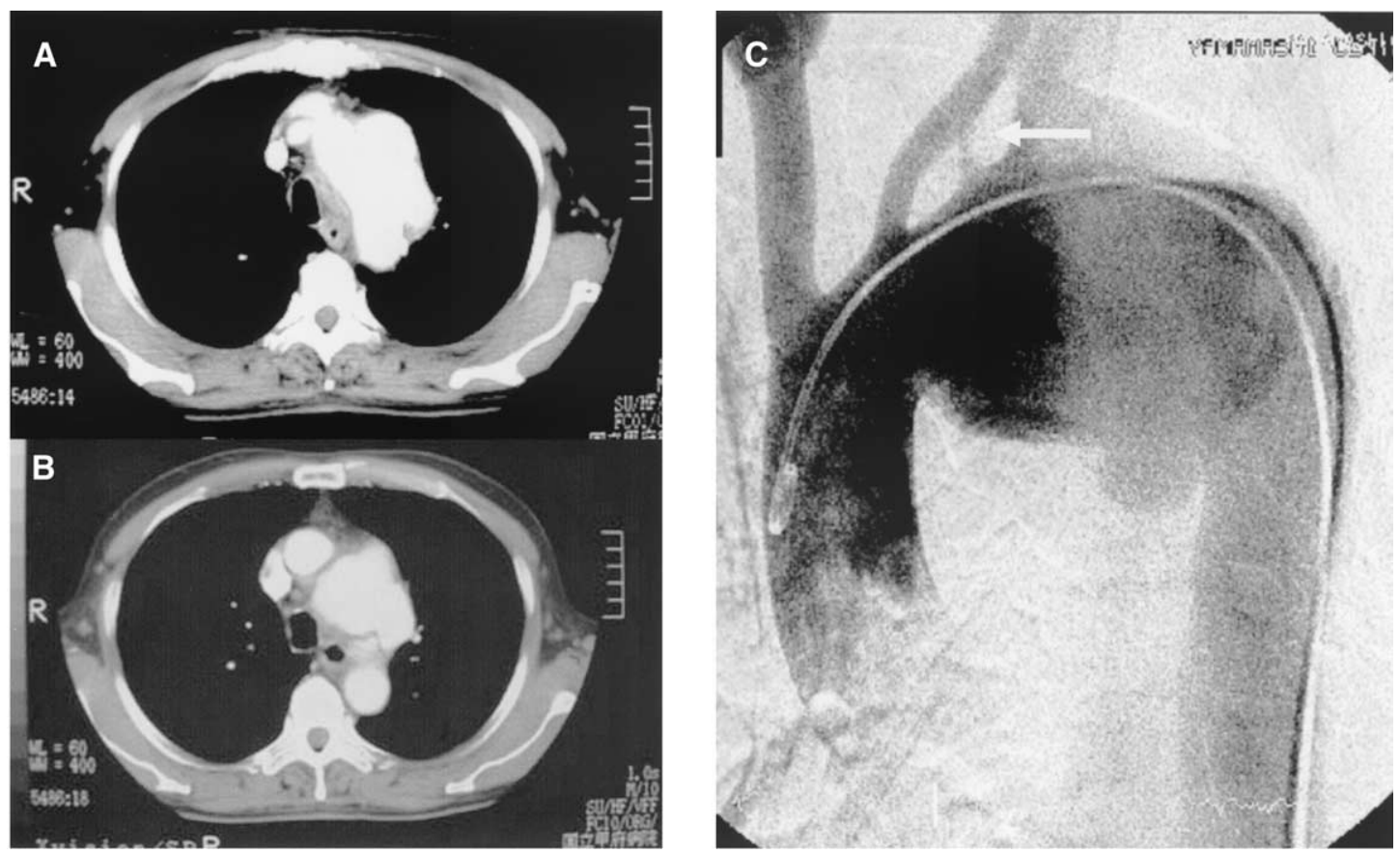

Figure 1. Preoperative computed tomography (A, B) revealed multisaccular aneurysm of aortic arch suggestive of mycotic aneurysm. Digital subtraction angiography (C) revealed ILVA (arrow) arising from aneurysmal wall.
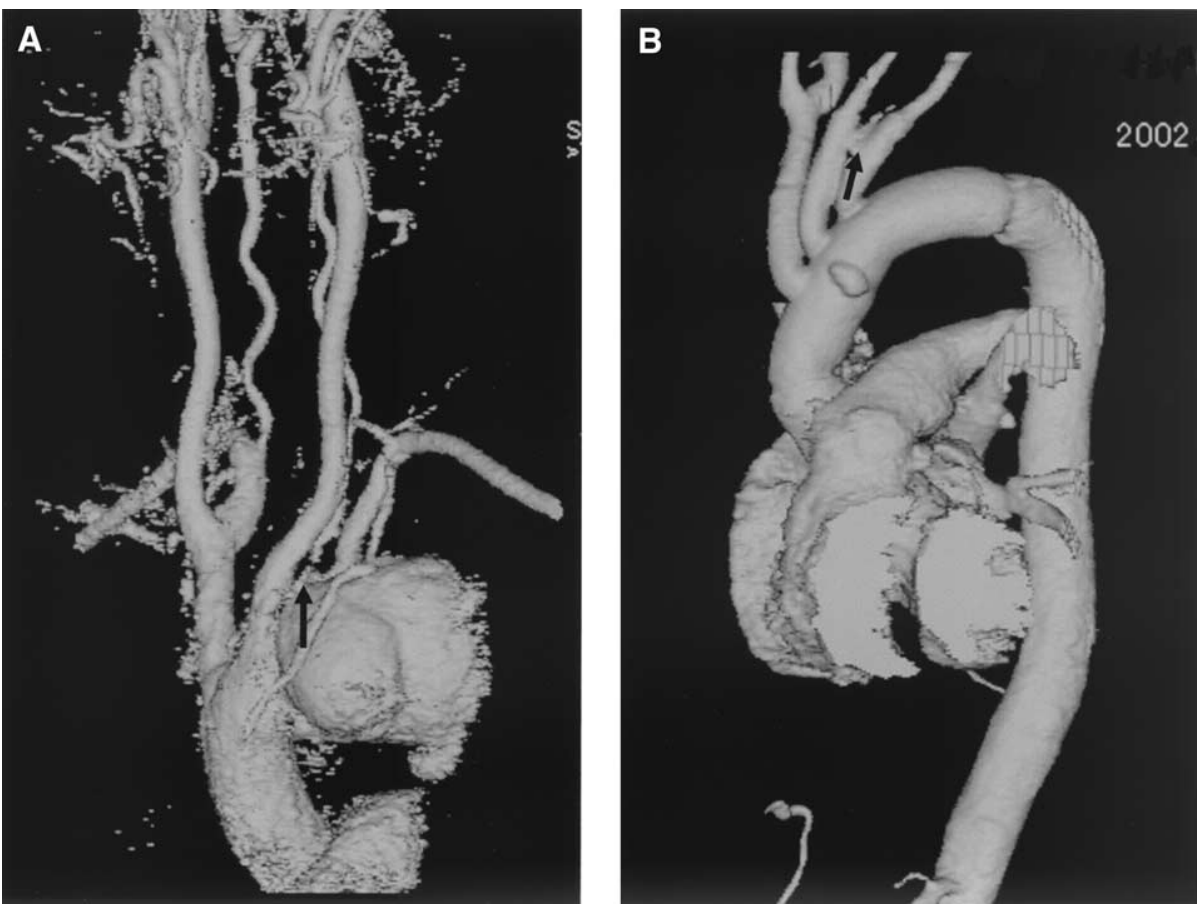

Figure 2. A, Preoperative magnetic resonance angiography showed ILVA (arrow) arising from aneurysmal wall. B, Postoperative magnetic resonance angiography showed reconstructed ILVA (arrow) to be patent. 
postoperative day 19. His 6-month follow-up examination showed no recurrence of the infection.

\section{Discussion}

Mycotic aortic aneurysm is an extremely rare complication of arterial infection, accounting for fewer than $1 \%$ of aortic aneurysm repairs. The bacterial organisms commonly identified include Staphylococcus aureus, Staphylococcus epidermidis, Salmonella species, Streptococcus species, Haemophilus influenzae, Pseudomonas species, Candida species, and Escherichia coli. ${ }^{1}$ Isolation of $S$ pneumoniae in the mycotic aneurysm seems to be rare; we have found only a few reports associated with this pathogen. ${ }^{2,3}$

It has been suggested that in situ insertion of cryopreserved aortic homograft would reduce the postoperative infection rate and improve survival of this group of high-risk patients ${ }^{4}$; however, most patients with mycotic aneurysm require emergency intervention, and access to a tissue bank is not feasible. In certain circumstances, such as active purulent infection by $S$ pneumoniae, homografts have been reported to fail. ${ }^{3}$

How to deal with the ILVA is debated. We decided to preserve our patient's ILVA for two reasons. One was that in certain aortic arch anomalies the left common carotid artery does not supply normal blood flow, and the ILVA compensates for this. ${ }^{5}$ Another was that if the vertebrobasilar axis is a dominant left axis or if communication at the arterial circle of Willis is poor because of another arterial lesion, elimination of the ILVA can cause ischemia of the brainstem and cerebellum. The approaches to ILVA reconstruction include en bloc reconstruction of the arch branches, direct anastomosis to the graft branch corresponding to the LSA, and direct anastomosis to the native LSA. ${ }^{6,7}$ Although there are no published long-term results concerning the patency of the reconstructed ILVA, we used a saphenous vein graft interposed between the ILVA and graft branch.

\section{References}

1. Svensson LG, Crawford ES. Cardiovascular and vascular disease of the aorta. Philadelphia: Saunders; 1996.

2. Nijs A, Vandekerkhof J, Cartuyvels R, Magerman K, Mewis A, Peeters $\mathrm{V}$, et al. Streptococcus pneumoniae-infected aneurysm extending from a persistent lobar pneumonia: case report and review of the literature. Eur J Clin Microbiol Infect Dis. 2002;21:389-92.

3. Berdat PA, Malinverni R, Kipfer B, Carrel TP. Homograft failure in mycotic aortic aneurysm caused by Streptococcus pneumoniae. Ann Thorac Surg. 1998;66:1818-9.

4. Vogt PR, Brunner-La Rocca HP, Carrel T, von Segesser LK, Ruef C, Debatin J, et al. Cryopreserved arterial allografts in the treatment of major vascular infection: a comparison with conventional surgical techniques. J Thorac Cardiovasc Surg. 1998;116:965-72.

5. Ad N, Lee P, Cox JL. Type A aortic dissection with associated anomaly of the carotid and vertebral vessels. J Thorac Cardiovasc Surg. 2002; 123:570-1.

6. Kazui T, Washiyama N, Muhammad BA, Terada H, Yamashita K, Takinami M. Improved results of atherosclerotic arch aneurysm operations with a refined technique. J Thorac Cardiovasc Surg. 2001;121: 491-9.

7. Nonami Y, Tomosawa N, Nishida K, Nawata S. Dissecting aortic aneurysm involving an anomalous right subclavian artery and isolated left vertebral artery: case report and review of the literature. $J$ Cardiovasc Surg (Torino). 1998;39:743-6.

\title{
Successful LVAS and RVAS-ECMO support in a patient with fulminant myocarditis who failed to recover from ventricular fibrillation with PCPS and IABP
}

\author{
Satoshi Gojo, ${ }^{a}$ Shunei Kyo, ${ }^{\mathrm{a}, \mathrm{b}}$ Hiroshige Sato, ${ }^{\mathrm{a}}$ Motonobu Nishimura, ${ }^{\mathrm{b}}$ Toshihisa Asakura, ${ }^{\mathrm{a}}$ Hiroyuki Ito, ${ }^{\mathrm{c}}$ and

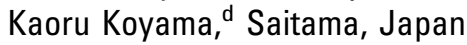

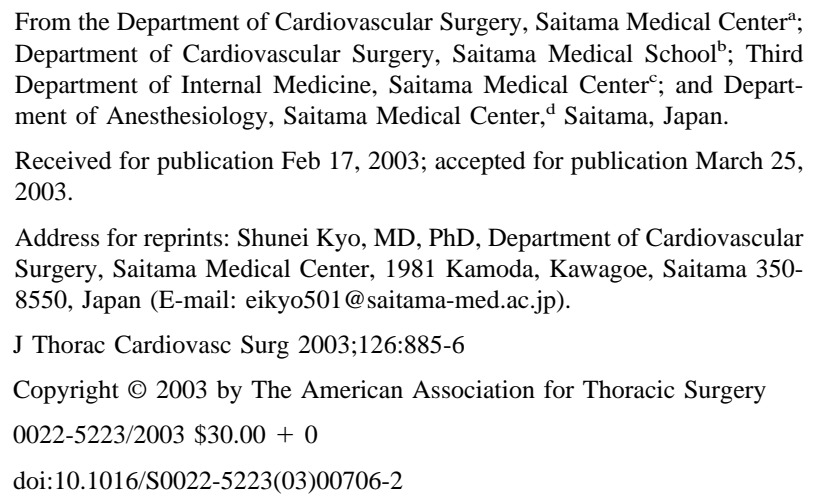

From the Department of Cardiovascular Surgery, Saitama Medical Center ${ }^{\mathrm{a}}$ Department of Cardiovascular Surgery, Saitama Medical School ${ }^{\text {b }}$; Third Department of Internal Medicine, Saitama Medical Centerc; and Department of Anesthesiology, Saitama Medical Center, ${ }^{\mathrm{d}}$ Saitama, Japan.

Received for publication Feb 17, 2003; accepted for publication March 25, 2003.

Address for reprints: Shunei Kyo, MD, PhD, Department of Cardiovascular Surgery, Saitama Medical Center, 1981 Kamoda, Kawagoe, Saitama 3508550, Japan (E-mail: eikyo501@ saitama-med.ac.jp).

J Thorac Cardiovasc Surg 2003;126:885-6

Copyright $\odot 2003$ by The American Association for Thoracic Surgery $0022-5223 / 2003 \$ 30.00+0$

doi:10.1016/S0022-5223(03)00706-2

$\mathrm{F}$ ulminant myocarditis can cause sudden circulatory collapse due to lethal arrhythmia, which is resistant to conventional treatments such as percutaneous cardiopulmonary support (PCPS) and intra-aortic balloon pumping (IABP). We describe the case of a young patient with fulminant end-stage myocarditis who was unable to recover from ventricular fibrillated (Vf) cardiac condition even with PCPS and IABP and who achieved recovery using a left ventricular assist system (LVAS) and a right ventricular assist system (RVAS) with extracorporeal membrane oxygenation (ECMO).

\section{Clinical Summary}

Myocarditis remains a poorly characterized disorder, and it is sometimes difficult to make an early diagnosis. ${ }^{1}$ Although patients 